\title{
Are the cerebral ventricles involved in thirst produced by a cholinergic substance?
}

\author{
ROBERT D. MYERS AND THEODORE J. CICERO ${ }^{2}$ \\ LABORATORY OF NEUROPSYCHOLOGY, PURDUE UNIVERSITY
}

In an attempt to produce a dose-dependent polydipsia, carbachol was chronically infused into the lateral cerebral ventricles of rats. Five drug-schedule combinations were employed and, as a control, saline and norepinephrine infusions were also given. Repeated intraventricular micro-injections, over 26 days, of carbachol and the other compounds failed to produce significant changes in water or food intakes in excess of normal baseline levels. These results suggest that the drinking following the application of carbachol to any of a number of limbic structures is not mediated by the cerebral ventricular route.

If a cholinergic substance such as carbamyl choline (carbachol) is applied locally to any of a number of subcortical structures in the rat, excessive drinking often occurs (Fisher \& Coury, 1960; Coury, 1967). The anatomical diffuseness of this effect has led to the hypothesis that carbachol may diffuse from its site of application into the cerebral ventricles and, via this route, exert its polydipsic action on the brainstem regions involved in drinking (Routtenberg, 1967). This study was carried out to determine whether chronic micro-injections of a cholinergic compound into the cerebral ventricles would produce a dosedependent polydipsia.

\section{Method}

Under Nembutal anesthesia, a lightweight intraventricular cannula (Myers et al, 1967) was implanted in each of 12 male hooded rats, 120 days of age. The cannula was placed stereotaxically in a lateral ventricle, according to the DeGroot (1959) coordinate system, at AP: 5.6; Lateral: 2.0; and Horizontal: +2.5. Prior to surgery, water and food intakes were recorded for 13 days and postoperatively for four days. The animals were then divided into two groups: eight rats in a carbachol-injected group and four rats in a saline-injected group.

A multi-channel chronic infusion system (Myers, 1963) was used for micro-injection of drug solutions administered always in a $1 \mu l$ volume. Carbachol was dissolved in sterile saline and micro-injected according to predetermined schedules in five doses ranging from $3.40 \times 10^{-10}$ mole $(0.5 \mu \mathrm{g})$ to $21.77 \times$ $10^{-10}$ mole $(3.2 \mu \mathrm{g})$ per hour. Each dose was given around the clock for 3 to 6 consecutive days to every animal with a one to two day rest period between each infusion regimen as a precaution against cumulative drug effects. In the control rats, 0.9 percent saline solution was infused intraventricularly on the same schedules as the carbachol animals. Water and food intakes were recorded at regular daily in- tervals prior to and during the 26 days of chronic micro-infusion.

\section{Results and Discussion}

In comparison to the 16 day preinfusion baseline levels, water intakes failed to increase appreciably at any dose of carbachol. In fact, the highest dose of carbachol caused a cessation of drinking as well as eating in several rats after one to two days of infusions; also at this dose level, toxic effects were observed including severe motor disturbances and epileptiform seizures similar to those described previously (Myers, 1964a; Fisher \& Levitt, 1967). In the four control rats, food and water consumption also did not deviate from the normal baseline. Fig. 1 shows the mean water and food intakes under all infusion conditions for the carbachol and salineinfused rats. The infusion schedule $(C$ to $G)$ is given in the legend. Notable fluctuations in food and water intakes occurred in both groups under several schedules. For example, in the carbachol group, food consumption was elevated when $2.0 \mu \mathrm{g}$ of carbachol was micro-injected over an hour period; how-

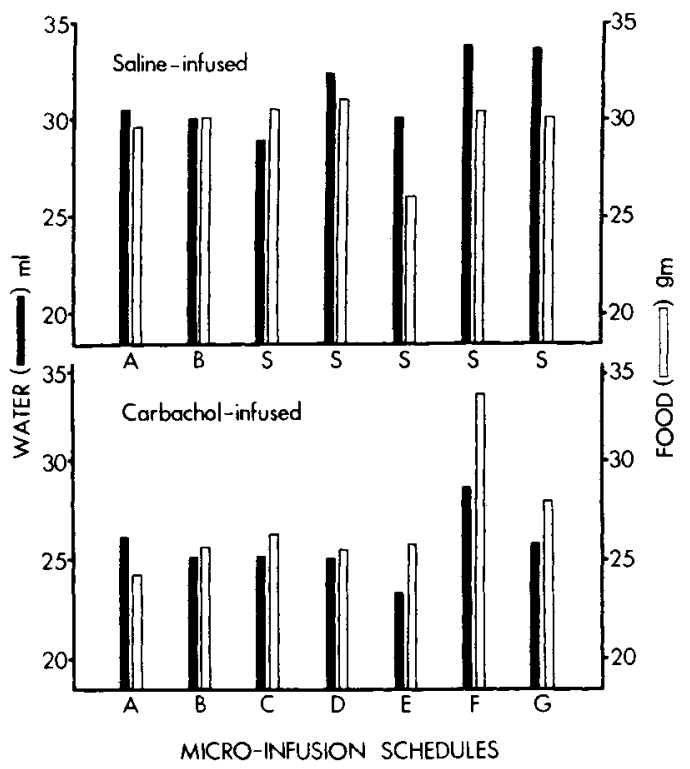

Fig. 1. Mean daily water and food intakes for saline infused rats (upper) and carbachol infused rats (lower) under all micro-infusion schedules. Experimental conditions are coded as follows: A: Preoperative baseline; B: Postoperative baseline: S: $0.9 \%$ saline control infusions; $C$ : $5.44 \times 10^{-10}$ mole $(0.8 \mu \mathrm{g})$ per hour; $D: 21.77 \times 10^{-10}$ mole $(3.2 \mu \mathrm{g})$ per hour; E: $3.40 \times 10^{-10}$ mole $(0.5 \mu \mathrm{g})$ per hour; $F$ : $13.67 \times 10^{-10}$ mole $(2.0 \mu \mathrm{g})$ per hour; $\mathrm{G}: 10.88 \times 10^{-10}$ mole $(1.6 \mu \mathrm{g})$ per hour given once every 12 hours. 


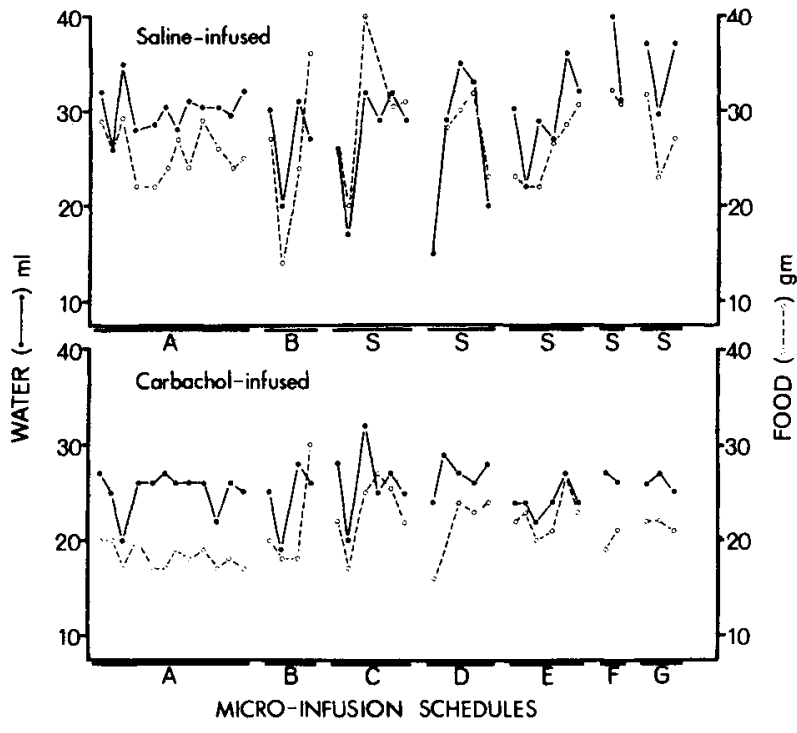

Fig. 2. Representative daily water and food intakes for a saline infused mat (upper) and a carbachol infused rat (lower) under all micro-infusion schedules. Legend is as in Fig. 1.

ever, none of these deviations was statistically significant. Figure 2 illustrates typical individual intakes of food and water for a carbachol and a salineinfused rat. Once again, day to day variations in intakes were observed although no significant, consistent alteration resulted. At the conclusion of the carbachol infusion series, atropine and noradrenaline also were micro-injected intraventricularly for one and five days, respectively. These compounds, when given by this route, likewise did not cause an increase in water or food consumption.

As a morphological control, a solution of bromophenol blue was micro-injected in volumes equivalent to those of the carbachol injections. Post-mortem examinations revealed that the dye was transported throughout the entire ventricular lumen, including the side contralateral to the cannula site.

In view of these results, the suggestion that carbachol exerts its polydipsic action by way of the ventricular route does not appear to be valid. It would appear that neither the milieu of the cerebrospinal fluid nor possible chemo-specific receptor sites lining the walls of the ventricular system are involved in the mediation of drinking.

Though these data may help to clarify one issue, the question of the unusual morphological diffuseness of the "cholinergic drinking circuit" in the rat is not explained. In this connection, there are several other puzzling phenomena, including phylogenetic irregularities, which seem to arise as each new species is examined. For instance, carbachol injected in minute amounts into the lateral hypothalamus produces a rage response in the cat (Myers, 1964) but eating in the rabbit (Novin, 1968). When this compound is micro-injected in the lateral hypothalamus of the rhesus monkey, drinking and eating cease even in the thirsty and hungry monkey, an effect which can be reversed by atropine (Myers, 1968). Further, at an homologous site in the cat, the micro-injection of noradrenaline causes drowsiness (Myers, 1964 b), whereas passage of an electric current can evoke a feeding response (Hess, 1957).

These evolutionary and structural pecularities are in a sense not easily comprehensible. Clearly, the relatively new method of chemical stimulation of brain tissue presents an extraordinarily complicated approach to the physiology of the brain.

\section{References}

COURY, J. N. Neural correlates of food and water intake in the rat. Science, 1967, 156, 1763-1764.

DeGROOT, J. The rat forebrain in stereotaxic coordinates. Verhandel. Koninkl. Ned. Akad. Wetenschap. Afdel. Natuurk., 1959.

FISHER, A. E., \& COURY, J. N. Cholinergic tracing of a central neural circuit underlying the thirst drive. Science, 1960, 132, 301-302.

FISHER, A. E., \& LEVITT, R. A. Drinking induced by carbachol: Thirst circuit or ventricular modification? Science, 1967, 157, 838-839.

HESS, W. R. The functional organization of the diencephalon. Grune and Stratton, London, 1957.

MYERS, R. D. An intracranial chemical stimulation system for chronic or self-infusion. J. Appl Physiol, 1963, 18, 221-224.

MYERS, R. D. Modification of drinking patterns by chronic intracranial chemical infusion. In M. Wayner (Ed.) Thirst in the regulation of body water. Oxford: Pergamon Press, 1964a, 533-551.

MYERS, R. D. Emotional and autonomic responses following hypothalamic chemical stimulation. Canad. J. Psychol 1964b, 18, 6-14.

MYERS, R. D. Chemical mechanisms in the hypothalamus mediating eating and drinking in the monkey. In Neural regulation of food and water intake. Ann. N. Y. Acad. Sci., 1968, in press.

MYERS, R. D., CASSADAY, G., \& HOLMAN, R. B. A simplified intracranial cannula for chemical stimulation or long-term infusion of the brain. Physiol \& Behav., 1967, 2, 87-88.

NOVIN, D. In Neural regulation of food and water intake, Ann. N. Y. Acad. Sci, 1968, in press.

ROUTTENBERG, A. Drinking induced by carbachol: Thirst circuit or ventricular modification? Science, 1967, 157, 838-839.

Notes

1. This research was supported in part by National Science Foundation Grant GB 3874, Office of Naval Research Contract N 0014-A-02260003 , Project NR-101-674 and by a grant from the Wallace Laboratories. 2. Fellow of the Purdue Research Foundation.

3. The authors are particularly indebted to P. F. East and M. Waller for their technical assistance throughout this research. 